\title{
The Influence of Wang Guowei's Ci-Style Oriented Thought
}

\author{
Yana Wu \\ Chinese Literature and Language, Southwest University, Chongqing, China \\ Email: wuyana1985@163.com
}

Received 13 September 2015; accepted 20 October 2015; published 26 October 2015

Copyright (C) 2015 by author and Scientific Research Publishing Inc.

This work is licensed under the Creative Commons Attribution International License (CC BY). http://creativecommons.org/licenses/by/4.0/

c) (i) Open Access

\begin{abstract}
Wang Guowei is the founder of external Ci system in the late Qing Dynasty and early Republic of China. His Ci-style Oriented thought, based on the western literary theory, fits the contexts of intersection of ancient and modern Chinese and western culture in the 20th century, colliding with the internal $\mathrm{Ci}$ system and resonating with external $\mathrm{Ci}$ system. In the collision and blending of ideas, Wang's thought promoted the modernization process of the $\mathrm{Ci}$.
\end{abstract}

\section{Keywords}

Wang Guowei, Ci-Style Oriented Thought, The Internal Ci System, The External Ci System, Influence

\section{Introduction}

If modernity is the dominant theme of Chinese social life in the 20th century, then the absorption, criticism and transformation of modernity means the continuous shock and evolution of thoughts, resulting in the evolution of the literature concept. Wang Guowei was the first one to introduce western aesthetic theories and created the Ci-style oriented thought from the perspectives of Ci-style, Ci-sentiment, Ci-situation, Ci-body, etc. His ideas corresponded to the New Culture Movement, and he was regarded as the pioneer of May 4th poetry revolution. The Ci-style oriented thought is a mirror of social and political reform and cultural thinking trend in the field of modern poetry, which empties into the torrent of ideological and cultural movement, i.e. Revolution in of Poetry Circle, Revolution in Fiction Circle, Theatrical Revolution and New Style. As the founder of the external Ci-system [1], Wang's thought must have exerted a significant impact on both the internal and external Ci-system in late Qing Dynasty. However, there are still two questions to be solved. To begin with, how did his genre thought influence the two Ci-systems? Secondly, what is the fundamental contradiction between them? 


\section{The Collision between Wang's Ci-Style Oriented Thought and Internal Ci-System Thoughts}

In the late Qing Dynasty, the internal Ci-system was represented by four great poets [2], who broke the barriers that were established by the two factions, namely the Changzhou Poetic Style of Ci and the Zhe Xi Poetic Style of $\mathrm{Ci}$ and then integrated the rhythm and the forms into the Ci-style oriented thoughts [3]. However, the four great poets placed so much emphasis on prosody that the lyrics were usually unfamiliar words, making it less vivid and natural [4], exposing the rotting of Ci. Wang Guowei witnessed the malady, hence he referred the western philosophy, advocating true and natural realm, criticizing the polish and shallow of Mengchuang $\mathrm{Ci}$, and striving to reform $\mathrm{Ci}$ from literature angle. However, due to the forces at a time when conventional $\mathrm{Ci}$ was blazing, nobody spoke highly of Wang and his Of Poetry in united silence [5], which, however, was gradually broken due to the change of time.

The outbreak of the revolution of 1911 has witnessed the great changes of political system and economic system in China, which also brings new changes in Ci-ecological environment, like the poet community, School of $\mathrm{Ci}$, the publication of words, etc. [6] Sponsored by Long Yusheng, the Ci Poetry Quarterly and the Simultaneous Monthly started their publication successively, becoming two debating platforms for poets within Ci system. And Southeast University is the Ci-base of internal $\mathrm{Ci}$ system, attracting great number of poets, such as $\mathrm{Hu}$ Xiansu, Wu Mei and other artists, who continued to canonize $\mathrm{Ci}$ and keot the traditional ways of Ci.

There were a lot of traditional poets against Wang in the internal Ci system. Wang Yi regarded Of Poetry as Wang Guowei’s early work [7], and Zhang Ertian also mentioned about Wang Guowei's old deep regret of his own early works [8], attempting to subvert the modern Ci-style oriented thought. Furthermore, Tang Guizhang criticized Wang Guowei's Realm Theory, saying that emotional prosody should not be replaced by Realm Theory [9]. Sun Renhe attacked the Realm with Me and the Realm without Me in Wang Guowei's Of Poetry, in an attempt to deconstruct the Realm Theory. He held that one had the seven emotions and the description of a beautiful picture usually depended on his or her emotions. If there is a realm without one, it will be nothing [10].

Although the writers from internal Ci-system had enough testimony to utmostly criticize Wang's thoughts, they had to change their attitudes gradually along with the publication of Rejian Cihua and the expansion of Wang's Ci-style oriented thoughts. Wang Guowei’s works including Ren Jian Ci Hua were quoted by many works such as Ye Gongchao's Ci in Guangqie, Long Yusheng's Famous Ci in Recent Three Hundred Years, Chen Yunzhang's Eminent Poets' Ci in Qing Dynasty. Ye Gongchao demonstrated the essence [11]. Lu Qian also praised Ren Jian Ci Hua for its realm-oriented theory thought highly of the North Song Ci, which was full of insight [12]. It is evident that Wang's theory has penetrated into the internal system. Therefore, Zhang Ertian was surprised about Wang and spoke highly of Ren Jian Ci Hua and Realm Theory, making no difference between $\mathrm{Ci}$ and Vermacular Chinese [13]. However, Zhang's rallying cry still cannot stop the strong advance of modern Ci.

Long Yusheng, as a disciple of Zhu Zumou, can still feel the full flavor of the times. He criticized that the University Ci club in the decline and fall of the country was indulged in verbiage and placed too much emphasis on the word rhyme, which echoed with Wang Guowei's natural view of Ci. Long Yusheng also held one view of poetry and $\mathrm{Ci}$, strove to enhance the appreciation, and emphasized that the lyrics should be about the history and true feeling [14]. He also adopted scientific methods to carry out the Ci criticism, and wrote a lot of papers which contain macroscopic consciousness and modern characters, and facilitated the modern evolution of Ci.

Xia Chengtao is not only a summarizer of the traditional Ci studies, but also a pioneer of the modern Ci studies. Influenced by Wang Guowei, he objectively examined the development history of three hundred years from the perspective of evolution [15]. In addition, Xia advocated easing Ci prosody view, and held that Ci can be broken without adherence to the four tones, which was more useful for the agreement between $\mathrm{Ci}$ and era [16]. Thus, the influence of Wang's Ci-style oriented thought on the internal Ci system was pretty subtle.

\section{The Resonance of Wang's Thoughts and Thoughts of External Ci System}

Wang Guowei, as a pioneer for the external Ci system, exerted far-reaching influence on external Ci system and Ci studies. In 1922, the Chinese Classics Institute of Peking University was established. Hu Shi hired Wang Guowei, Chen Yinque etc. as the research mentors, then a new breed of poets gathered in the north and began to spread the theory of Ci.

Hu Shi's Ci study is greatly influenced by Wang Guowei. He completely got rid of the bondage of traditional 
concept, regarding the $\mathrm{Ci}$ for living literature and Baihua Literature. He explored into the change of Ci-style from the view of historical evolution [17], making Ci even higher than the orthodox poetry in literature status. $\mathrm{Hu}$ also stressed that $\mathrm{Ci}$ should have expressive function and fresh language style, and therefore criticized Mengchuang Ci. Furthermore, based on Wang Guowei’s Realm Theory, Hu Shi adopted western academic thoughts and research methods, and established the view and framework of Ci history so as to fit the trend of the new culture movement at the first time [18], which makes Ci completely transform from the tradition to the modernization.

Yu Pingbo, the author of New Trend, first reedited Ren Jian Ci Hua in 1926, making it gradually attract the attention of academia, which led to a kind of phenomenon that once people discussed the Ci-poetics, they would not miss Ren Jian Ci Hua and the realm theory, which further expanded the influence of Wang's thought [19]. Hu Yunyi received a deeper influence from Ren Jian Ci Hua and his The Study of Song Ci, for the first time, adopted modern vision and systemic writing style to describe the evolvement process of Song Ci [20], which was a logo for the transformation from traditional Ci studies to modern ones.

\section{Conclusion}

Wang Guowei's Ci-style oriented thought has infiltrated into many fields of $\mathrm{Ci}$ in the Republic of China. Influenced by Wang Guowei's Ci studies, the Ci-potery research paid more attention to the reformation to the theory of Ci-style, excavating emotion and charm, exploring the aesthetic realm, building $\mathrm{Ci}$ system, and reshaping concept of Ci history. Wang disseminated the western literary theory and fitted the context of intercultural communication in the 20th century. The followers from the external Ci-system adopted Wang's theory, while the researchers from the internal Ci-system also followed Wang's theory. Both of them were devoted themselves to promoting the quintessence of Chinese culture, rearranging the national heritage, developing the theory of $\mathrm{Ci}$ style with no essentiality contradiction. However, their effort has promoted the evolution of the Ci-ology together with the debates. Wang carried new ideas and new methods, found new path for Ci studies, which made him become the first person with cross-time significance in the change of $\mathrm{Ci}$ theories and criticism in the 20th century.

\section{References}

[1] Hu, M. (1998) Studies on Ci over the Past Century: Interpretation and Thinking. Literature Legacy, 2, 21.

[2] Sun, K.Q. (2006) The Epitomization of the Ci-Ology for the Four Great Poets in the Late Qing Dynasty. Theoretical Studies in Literature, 3, 109.

[3] Kuang, Z.Y. (2000) Preface of Canyingci. Jiangxi People Press, Nanchang, 594.

[4] Long, Y.S. (1997) The Change of Ci-Style in Late Qing Dynasty. In: Long Yusheng's Collection of Ci Papers, Shanghai Ancient Books Press, Shanghai, 84.

[5] Wang, S.Z. (2008) Kuang Zhouyi and Wang Guowei: Two Aesthetic Patterns. Literature Legacies, 2, 8.

[6] Cao, X.H. (2008) The New Changes and Cultural Significance of Ci of Republic of China. Jianghai Journal, 4, 181.

[7] Wang, Y. (1937) Quotation from Xu Xingye, An Introduction of Critics of Ci in Qing Dynasty. Wuxi College of Chinese Culture, Wuxi.

[8] Zhang, E.T. and Long, Y.S. (1933) An Review of Ci Studies. Ci Study Quarterly, 1, 4.

[9] Tang, G.Z. (1941) An Review of Ren Jian Ci Hua. In: Zhang, Z., Ed., Successive Dynasties of Poetry Sequel, The Daxiang Press, Zhengzhou, 920-922.

[10] Sun, R.H. (1996) An Abstract of Ren Jian Ci Hua, An Abstract of Revision of Si Ku Quan Shu, Volume 13. Qilu Books Press, Jinan, 568.

[11] Ye, G.C. (1998) Guang Xia Zhong Ci. Zhejiang Ancient Books Press, Hangzhou, 2, 674.

[12] Lu, Q. and Wang, J.N. (2005) Hundreds of Ci Poets of Qing Dynasty. In: Zhang, Z., Ed., Sequel of Ci Hua of Each Dynasty, The Elephant Press, Zhenzhou, 1072.

[13] Zhang, E.T. (1941) Of Ci Books with Long Yusheng. Tongsheng Quarterly, 1, 8.

[14] Long, Y.S. (1997) Long Yusheng's Collection of Ci Studies. 114.

[15] Xia, C.T. (1988) Preface of the Essence of Ci. In: Collections of Xia Chengtao, Volume 8, Zhejiang Ancient Books Press, Hangzhou, 251. 
[16] Xia, C.T. (1988) The Evolution of Pronunciation of Ci from Tang Dynasty to Song Dynasty. In: Collections of Xia Chengtao, Volume 2, Zhejiang Ancient Books Press, Hangzhou, 81-82.

[17] Hu, S. (1991) Preface of Collections of Ci. In: Wu, B.X. and Li, X.H., Eds., Hu Shi Poetry, Sichuan Wenyi Press, Chengdu, 34.

[18] Yang, H.M. (1996) Theories of Ci Studies and the modernization of Critics of Ci Studies. Literature Comments, 6, 115.

[19] Chen, S.Y. (2012) Ren Jian Ci Hua and Modern Ci stUdies in China. Xiamen University Journal (Philosophical and Social Science Version), 2, 50.

[20] Wang, Z.P. (2001) Ci Studies during the First Half of 20th Century. Literary, 5, 106-113. 